\title{
Artículos
}

\section{Alberto Fuguet, un (in)digno descendiente de una buena tradición*}

\author{
María Nieves Alonso \\ Universidad de Concepción, Chile \\ E-mail: malonso@udec.cl \\ RESUMEN \\ M ala onda (1993) se inscribe en el corpus de novelas chilenas de aprendizaje y deforma- \\ ción del héroe. En este grupo se destacan, por crear relatos y personajes paradigmáticosy \\ ejemplares, muy especialmente M artín Rivas(1861) deBlest G ana e H ijo deladrón (1951) \\ deM anuel Rojas. El carácter interrogativo, la constante ironía, el modelo agencial elegido, \\ la estructura y los contenidos del relato y formas del discurso de la novela de Fuguet \\ subvierten los modelosmencionados, historizan un mito de la novela chilena, parodiando \\ el discurso canónico problematizando el salón, un espacio privilegiado por la novela ante- \\ rior ya subvertido por Donoso y Eltit, y desacralizando el esquema de la novela familiar \\ canónica relacionada, positiva y negativamente, pero siempre de forma unívoca, con el \\ poder, el saber y la figura del padre.
}

Palabras claves: Canon, novela, aprendizaje, desacralización.

ABSTRACT

M ala onda (1993) forms part of a corpus of Chilean novels of learning (bildungsroman) and of the formation of the hero. W ithin this group novels like M artin Rivas (1861) by Blest Gana and H ijo de ladrón (1951) by M anuel Rojas stand out, due to their creation of paradigmatic and exemplary tales and characters. The interrogatory character, the constant irony, the selected model of agency, the structure and contents of the story, and the forms of discourse of Fuguet's novel subvert the above mentioned models, historicizing a myth of the C hilean novel, parodying canonical discourse and problematizing the drawing room or salon, a privileged space in previous novels already subverted by D onoso and Eltit, and desacralizing the scheme of the canonical family novel, positively and negatively, but al ways in a univocal form, with the power, the knowledge and the figure of the father.

Keywords: C anon, novel, learning, desacralization.

Recibido: 15-03-2004. Aceptado: 10-08-2004.

*Este trabajo corresponde al Proyecto FON DECYT N 01020321 año 2002. 


\section{INTRODUCCION}

M ALA ON DA (1993) de Alberto Fuguet se inscribe en el corpus de novelas chilenas de aprendizajey formación del héroe. En este interesante grupo, en el cual pueden incluirsetextos como U n idilio nuevo (1900) de 0 rrego Luco, El crisol (1913) deFernando Santiván, El roto (1920) deJoaquín EdwardsBello, Un perdido (1917) deEduardo Barrios, Los hombresoscuros (1939) deN icomedes Guzmán, destacan muy particularmente M artín Rivas (1861) de Alberto Blest Gana e Hijo de ladrón (1951) de M anuel Rojas. Esto porque aparte del valor e interés narrativo, señal ado reiteradamente, en estas dos novelas, ellas, a través de sus héroes, muestran la profunda tran fformación de los valores sociales que el héroe busca, adquiere y afirma y una radical transformación en el modo de exponerlo,

desde la confiada afirmación de un "saber" y de una axiología para si empre ya determinada a una precaria "búsqueda" de significados inestables y a un constante desplazamiento del orden en el mundo imaginado. Así, a partir de su mismo título y de su compacto lenguaje asertivo, $M$ artín Rivas propone inequívocamente la noción de personaje en todo su esplendor, Hijo de ladrón constituye un hito capital en el proceso desconstructivo al que lo somete la narrativa contemporánea y que en la novela chilena encuentra una primera culminación - mediantela erosión de la estabilidad de las relaciones lingüísticas y narratológicas que sostienen su "personalidad"- en El obsceno pájaro de la noche (1970) de osé D onoso para continuarse luego - bajo muy distintas condiciones sociales y estéticas- en novelas como El arte de la palabra (1980) de Enrique Lihn y Lumpérica (1983) de Diamela Eltit (Soto 1992:23)

y en el espejo irónico, deformante de M ala onda de Alberto Fuguet.

Volviendo a los dos modelos privilegiados, se observa que los héroes de $\mathrm{M}$ artín Rivas e H ijo de ladrón viven procesos que les permiten iniciar, o estar listos para iniciar, un proyecto de vida, incorporándose, en el primer caso, con plenitud al centro social y al poder burgués $y$, en el otro, a un grupo - colectivo se diría hoy- con el cual continuar y compartir una andadura y una ideología. En ambos casos se trata de la adquisición de lazos de (a)filiación y de la construcción de héroes ejemplares en cuanto conquista de un saber y el ejercicio adecuado y consecuente del mismo. Esto, al punto de poder afirmarse que " $M$ artín Rivas de Alberto Blest $G$ ana constituye el mito por excelencia de la novelística chilena" y que H ijo de ladrón construye un modelo de desarrollo de la constitución del héroe transgresor y anarquista 0 , en otro nivel, que

a pesar del inmenso éxito de novelas recientes como La casa de los espíritus 
(1982) del sabel Allende, sin duda, M artín Rivas eH ijo deladrón son aún dos de las novelas nacionales más conocidas en $C$ hile. Esta situación cobra mayor interés toda vez que la novela de $M$ anuel Rojas se ubica estética e ideológicamente en una radical oposición crítica con respecto de la de Alberto Blest Gana (Soto: 70).

En estas novelas, antepasadas directas de la obra de Fuguet, y en la misma $M$ ala onda de este autor, se aprecian todos los aspectos que, según Joseph Campbell, se observan en el proceso de formación del héroe como también aparecen las secuencias, personajes y acciones queSusan Suleiman determina en los relatos de aprendizaje y, cómo no, los rasgos que, con anterioridad, G eorge Lúkacs ha estudiado respecto del héroe novelesco. La llamada de la aventura, el cruce del $1^{\text {er }}$ umbral, el encuentro con la diosa (o con los otros, en el caso de Rojas), la reconciliación con el padre, la búsqueda de la libertad para vivir, la adquisición de un saber, el reconocimiento, el viaje, las pruebas, los obstáculos, los colaboradores, el relato o inclusión de otras historias, la transformación del héroe pasivo en sujeto activo de su proyecto... son secuencias, motivos y aspectos que pueden reconocerse en estos textos que es posible leer con la guía de los model os de Campbell y Suleiman.

En relación al protagonista, en estos relatos destaca un rasgo fundamental. Se trata, en el inicio de la historia, de héroes que exhiben una carencia o falta que deberán suplir, anular o resolver en el transcurso del relato para aś sumar al deseo de ser, la capacidad y el poder para realizar el proyecto intuido y trazado por el conocimiento del mundo y la realidad en que se inscribe la historia:

Cuando la misión del héroe se ha llevado a cabo, por penetración en la fuente o por medio dela gracia de al guna personificación masculina o femenina, humana 0 animal, el aventurero debe a regresar con su trofeo, transmutador de vida.

$\mathrm{El}$ ciclo completo, la norma del movimiento, requiere que el héroe empie ce ahora la labor de traer los misterios de la sabiduría, el vellocino de oro, o su princesa dormida al reino de la humanidad, don de la dádiva habría de significar la renovación de la comunidad, de la nación, del planeta o de los diez mil mundos (Campbell 1984: 179).

Esta es la gran exigencia y el proyecto del héroe mítico y/o épico. D el héroe novelesco, marcado por otros deseos-menores- y otras carencias-mayores-, se espera que logre adquirir ciertas armas, herramientas 0 artificios para poder acomodarse en el mundo y buscar otros caminos paralel os o desafiar un manda to. Setrata de incorporación a un mundo o el caminar por el mundo dotado de un bien que será el saber y la voluntad de ejercerlo... o de no hacerlo. La novela 
es, entonces, una biografía y una crónica social y sus personajesinteractuarán en un mundo significado por sus pulsiones personales y colectivas. Por eso el protagonista de Blest $\mathrm{G}$ ana, quien carece de medios económicos y es la afirmación del orden burgués, es postulado como el ciudadano que contribuye al progreso del país a través de la continuidad y de la estabilidad garantizada por el orden público y privado (Soto: 67). Rivas poseejustamente la virtud dela moderación y tienela voluntad, el entendimiento y la memoria para llegar a ser. El relato que cuenta sus peripecias de "provinciano en Santiago" se estructura como una "novela de pruebas", alejada de la parodia y la transgresión. Por su parte, el héroe de $M$ anuel Rojas, quien carece de papeles, es el protagonista de una historia de búsqueda de un destino en compañía, de la narración del encuentro de la solidaridad, la conquista del habla y la comunicación en un relato de relatos en el que se exponeel reverso de las cosas y del mundo - lo excluido en M artín Rivascon gran presencia de la risa y la ironía.

M artín Rivas e H ijo de ladrón están, pues, en la historia literaria, en la dinámica discursiva, en la que M ala onda se inscribe en 1991 con una historia que transcurre en Chile septiembre de 1980, con toda la carga significativa de esa fecha en nuestro país y en una época en la que, según se dice, en 0 ccidente ya no quedan bastillas que asaltar (Lyotard).

"Este es un libro sobre la familia, sobre Chile, la memoria y la historia". Así define Fuguet su último libro Las películas de mi vida (2003) en una entrevista al diario El Sur de Concepción (26 octubre 2003). Esta definición, perfectamente adjudicable o transferible a $M$ ala onda, revela la intención del autor por producir una(s) novela(s) situada(s) y articulada(s) por los retazos de la memoria y la subjetividad de los recortes de la historia. Al mismo tiempo, al hacer sistema con otras expresiones suyas en las que define a su primera novel a como producto de un deseo: "Yo quería leer la novela que nunca había leído en el colegio" (es decir, yo quería escribir la novela que... ), muestra la necesidad de reconstituir un orden ubicado es un espacio temporal. Q ueda, entonces, expuesta una intención y un lector ideal: él mismo en un tiempo pretérito; otro como él en el tiempo presente, héroe juvenil y lector adolescente para una novela que también, su autor lo ha dicho, debe mucho a Papelucho de su admirada M arcela Paz.

Fuguet, asimismo, dice escribir sobre al go que sabe, hablar de al go certero, pues, según su ética de escritura, "cada uno debe contar lo que le tocó". Lo visto y lo vivido, yo y mis circunstancias, biografía y crónica; continuidad y cambios, M ala onda es, o parece ser, un relato de aprendizaje de la década del 90 en Chile y una historia familiar desarrollada en el año 80. 


\title{
I. LA FORMACION DEL HEROE
}

\author{
No miréis a vuestro alrededor -dijo el héroe de \\ los apaches Jicarilla, matador de enemigos-. Es- \\ cuchad lo que digo. El mundo es del tamaño de \\ mi palabra.
}

Cambiar, cambiar, cambiar el mundo, observar cuánto han cambiado los héroes novel escos, no se trata aquí en $M$ ala onda de los sueños ni los proyectos burgueses de M artín Rivas; tampoco de la asunción de un proyecto revolucionario 0 transgresor. Tampoco M atías V icuña es un héroe mítico, épico, ni sus acciones están marcadas por un gesto propositivo de voluntad ni hay la intención de superar carencias, pasar pruebas o vencer obstáculos. El aburrimiento, la acidia y el hartazgo, la pequeñez, la permutación del proyecto por vacío, la carencia de sentido y/o libertad más allá de los límites de la jaula, el diferimiento obligado, el reemplazo de las grandes metáforas, la trivialización del lenguaje y, a pesar de ello, la persistencia del deseo de constituirse en sujeto de aprendizaje y un devenir, parecen indicar que en la novela de Fuguet asistimos a una (in)versión, (per)versión, (re)visión de los relatos de aprendizaje tradicionales y válidos como tales, según nuestra ética del sentido y la constitución de un héroe dotado del poder de elegir y/o dispuesto para cumplir el deber de cambiar el mundo 0 ajustarse 0 ajustarlo a él. D escripciones anafóricas de estados como "Estoy en la arena, tumbado, roja, pegoteado por la humedad, sin fuerzas ni siquiera para arrojarme al mar y flotar un rato hasta desaparecer" (p. 19), "Estoy en la arena, tumbado, roja, pegoteado por el sol primaveral que me penetra por los poros, sin fuerzassiquiera para metermeal mar..." (p. 176), proposiciones como "jalemos lo que hay que jalar que mañana será otro día" (p. 195) parecen definir un espacio narrativo en el cual todo se deja al arbitrio del sinsentido o al de un futuro sobre el que no se presupone la activación de la voluntad surgida del conocimiento. Sin embargo, están en el texto la ambigüedad y la verdad de la incertidumbre novel esca y, a veces, un aire, un viento, una brisa pura se cuelan entre las páginas del jale y la inconsciencia: "Respiro hondo para cambiar de tema: Siento el aire puro, como en Portillo al amanecer. Allá abajo, ni tan lejos, más allá de unas feroces casas tipo mediterráneo, está Santiago" (p. 79). Así uno podría decir quela novela, que describe un pequeño viaje hacia ese Santiago que está más allá de las mural las del feudo y que va hacia el padre, relata el traspaso de la mala onda y relata la adquisición de una fortaleza, exponiendo los efectos de una bajada a los infiernos, de la que se vuelve purificado y con otros deseos: "Empiezo a descender. La pendiente está brava y con cada pedaleo, más velocidad agarro. El viento es puro, tan helado que corta. Pero sigo, me gusta..." ( $p$. 335). Pero... todo eso parecetan menor, individual, ridículo y, a veces, patético. 
M uy bien, vuelvo atrás, y parto con una afirmación seductora y absoluta: M atías Vicuña, hijo de la burguesía arribista y trivial, es un anti M artín Rivas y, naturalmente, un anti Aniceto $\mathrm{H}$ evia. $\mathrm{M}$ ala onda es una parodia de las novelas de aprendizaje. En ella seha reducido al mínimo el espacio y valores del héroe, la ironía se ha vertido en sarcasmo, la liviandad ha usurpado el lugar del espíritu del progreso y dela libertad revolucionaria. N o hay ejemplaridad, el héroeno es encomio de virtudes, ni siquiera posee voluntad. Los oponentes a su proyecto son caricaturas, los aliados -Alejandro Paz, Flora M ontenegro o H olden Caulfieldparticipan en su "formación" pero no representan valores nítidos, admirables y constantes. El viaje puede considerarse grotesco en su miniatura y capricho, la amada no esemblema deningún éxito, el diálogo final con el padre-el destinador y opositor en los grandes relatos de aprendizaje es aquí una figura decadente primero y destruida después. Se podría decir incluso que $M$ ala onda es aquello queFlora M ontenegro dice quees El guardián entreel centeno: la novelita de "las peripecias y mañas deun adolescente judío malcriado y autorreferente" (p. 256) que no pueden interesarle real mente a nadie. Intenta crecer M atías, no tienes tamaño de héroe parece oírse, pero - el Coyote persigue a Correcaminos- algo se resiste a tales afirmaciones sobre esta novela, juvenil, qué duda cabe, en la que también atisban otros decires y deseos.

La novela de Fuguet, breve diario de doce días en la vida de un adolescente perdido, en crisis ciega, pero pronto activa, contiene, tal vez en forma residual, los rasgos de una novela de aprendizaje positivo en versión pop - pos moderna, aligerada por la distancia crítica con los grandes relatos modernos totalizadores y/o ideologizados. Es decir, M ala onda, como U n idilio nuevo o como El crisol, es un "bildungsroman" y, como tal, involucra una concepción de novela destinada a presentar aspectos y tramos de la vida humana y considera la acción formadora de los sucesos sobre el carácter del individuo en los años durante los cuales el hombre se forma: su adolescencia. Luego el héroe podrá iniciar otros caminos, vivirá otras aventuras.

Esta novela revela cómo el héroe adquiere un conocimiento de sí mismo - su origen escondido (judío-húngaro), sus limitaciones, su deber, al tiempo que reconoce el mundo que lo rodea y actúa en consecuencia. El resultado de este proceso es, en tiempo presente, un héroe eminentemente pasivo, ya que el conocimiento adquirido lo hace retraerse - acción válida- y le impide avanzar hacia otro lugar que no sea el de la protección y el resguardo, aunquetambién sea el de la espera:

Volví a mi casa, claro. Era lo que debía hacer, fue lo que deseaba. D udas tuve, las tengo y las tendré, pero más allá de lo plausible, del factor económico y legal, de todo aquello que parece ajeno einútil, pero está mucho más incrusta- 
do en mí de lo que estoy dispuesto a creer, sentí que me necesitaban -que me necesita mi padre y eso siempre es bueno, lo hace a uno olvidar, hasta empieza a perdonar. Pero no sólo es mi padre, soy yo (p. 332).

Esta afirmación del yo individual envía a la idea de que la novela es la historia de un alma queva por el mundo para aprender a conocerse, busca aventuras para probarse en ellas, y por ellas da su medida y descubre su propia esencia, expuesta por Suleiman para el "bildungsroman", eso sería lo que se realiza en $\mathrm{M}$ ala onda. Ahora, que el mundo descrito sea la negación de lo épico, elevado, ejemplar y utópico, eso es otra cosa.

Sí / N 0, autenticidad e inautenticidad: "El famoso Alejandro Paz de Chile, más allá de los golpes, no fue torturado ni nada. El dice que nos espera lo peor; que lo peor es justamente la calma, el hecho de acostumbrarse, yo le dije que quizás, pero ahora entendía mejor a los del sí, a los que votaron por mantener todo igual, porque, ahora sé, lo que más asusta es el cambio (...) sobreviví sí, concluyo, me salvé. Por ahora" (p. 335). Afirmación y relativización. M atías, como él mismo lo afirma, no es el mismo, algo ha cambiado en su existencia privada y los fantasmas están por todas partes. M atías, a través de su diario, va exponiendo su extrañeza y alteridad con el mundo, relata sus pequeñas aventuras, encuentra unos libros, unas palabras y adquiere un valor del que carecía al comienzo: la voluntad. Virtud del alma que, por ahora, ejerce para decidir volver a la casa del padre y no para emprender - al menos en el tiempo de lo relatado- su propia aventura que, sin embargo, están en algún tiempo y destino.

En otro aspecto, las categorías de sujeto, objeto, destinatario, están configuradas en un solo personaje, esto es en $M$ atías, quien tiene varios espejos en los cuales reflejarse o de los cuales huir: Alejandro Paz, Ximena Santander, el padre, C aulfield, Remsen: "Anoche conocí a H olden C aulfield. (...) H abía encontrado un amigo. M i mejor amigo. H abía encontrado un doble..." (p. 233). 0 tro destinador, el destinador separado del héroe, y que también puede funcionar como ayudante, pues transmite o quiere transmitir lo que sabe está representado en M ala onda por una pareja masculina familiar: padre y abuelo y una pareja literaria 0 artística: Caulfield y Remsen. Estos personajes pueden transmitir u obstaculizar la adquisición del saber buscado y beneficiarse 0 ausentarse de las acciones consecuentes. En un caso, se trata de la asunción de una filiación que obliga a permanecer y, en el otro, de una afiliación que proyecta y prefigura una conducta. Igualmente, y como en todo relato de aprendizaje, está presente la prueba de interpretación y se explicita(n) una(s) pérdida(s). En ésta(s) se incluyen las cosas y personas que $M$ atías echará de menos para siempre, la seguridad del hogar convencional, algunos amigos: Alejandro, Nacho, Luisa, Antonia: pero, fundamentalmente lo que se pierde es la inocencia, una inocencia que, es 
cierto, puede(con)fundirse, a veces, con la malcrianza y lafrivolidad. La trizadura de la ingenuidad, de la ignorancia, acristalada y olorosa, sobre el orden, permanencia de su mundo, está en la ironía del final y muy particularmentesignificada en el conocimiento del origen no castellano vasco de parte de su genealogía, en la traición de la madre y el espectáculo de la degradación del padre. Evidentemente, también, en el contacto con las zonas de peligro y los bárbaros que acechan tras las murallas del ghetto de las casas mediterráneas. Lo que afirmo es que Fuguet renueva y actualiza al model o y el modelo desublimando la secuencia de las peripecias exteriores e interiores del héroe, desacral izando la figura del padre y del padre de la madre, convirtiéndolos en fantoches de una comedia de apariencias y mentiras que, privadamente, se deshace por todas partes y que sólo se mantiene el equilibrio de la manipulación descrita estentóreamente por Carmen y por el triunfo del no cambio:

- ¿Tú crees que va a ganar el No, C armen?

- O ye, seré empleada y pobre, pero no por eso huevona, claro quevamos a perder. Pero no por eso no se puede alegar y revolverla un poco

- ¿Crees que van a arreglar la votación?

- Como dice mi comadre Iris, este país es tan cagado que ni siquiera van a tener que hacer trampa. Toda la gallada va a votar que Sí, y no sólo los ricos. En La Pintana, donde yo vivo, la mayoría apoya al culiado del Pinocho. Les ofreció unas cagadas de casas y los maracos entregan el poto a cambio... (p. 277).

El enemigo en todas partes. El hijo pródigo no tiene a quién suceder en la tarea de restablecer 0 consolidar un orden social perturbado 0 en proponer una sociedad diferente. Tampoco está preparado ni él ni el afuera, dominado por el "securitas" perversa. También, porque, como dice respecto de otro hecho opuesto a su propia acción, el de la falta del padre a recogerlo en la estación de autobuses, "se está sólo pero se está" y por ahora se debe continuar y soportar:

- Pensé que mi viejo me iba a venir a recoger - le dije al taxista. - ¿Perdón? 192)

- No, nada. N ada nuevo. No se preocupe. N ada que no pueda soportar ( $p$.

Parodia, cambio, continuidad, duplicaciones invertidas, la cuestión es queel protagonista de Alberto Fuguet termina recogiendo a su padre y tomará el encargo de poner orden en su mínimo mundo, realizando una de las funciones propias del héroe que es decidir-hablar-escribir, mostrando el proceso que le permite asumir un deber, reconocer su poder y (res)guardar su querer. Todo ello en el contexto de una sociedad de la que se nos dan noticias constantemente a través de fechas, sucesos, nombres, calles, revistas, etc. 
La duda era la siguiente: "¿M e voy o no me voy?". Virarse o volver, descender, ascender, descender. Los inicios que acompañan esta trayectoria, además de las marcas lingüísticas y los objetos del campo musical y audiovisual, se relacionan con el calor y el frío, un perfume (el Azzaro usado por el padrey "transferido" al hijo), la bicicleta, el guiño literario de ésta y, muy especialmente, con las señales leídas en ciertos textos, sobre los que volveré más adelante.

La simbología tradicional del frío, las alturas y el calor aparecen en la novela con bastanteintensidad. Así, el cal or, vinculado a la humedad del sudor, expresa en el plano dela vida espiritual un estado de inferioridad, tiene un valor enteramente negativo vinculado con la pasividad y la disolución. Por su parte, el frío y la frescura de lo alto se vinculan al anhelo de soledad, elevación y transformación y en la novela también proponen el gran valor del silencio tras la adquisición del habla y la posesión de la energía.

La bicicleta, hasta no hace mucho, medio de transporte y objeto de valor para un niño/joven, vincula la novela con el excelente relato "El ciclista del San C ristóbal", evocando una historia de relación filial y deformación positiva en la cual los verbos luchar, avanzar, reconocer, respetar son las marcas de la acción del héroe: querer compartir con su padre placer y expectativas. En este nivel, el delas acciones verbales, la novela de Fuguet reitera la conjugación de los verbos como apestar, jalar, cagar, salvarse, descender y, significativamente, la diada virarse/ volver y la oposición descender/ascender. Ello parece revelar el carácter de un relato en proceso y en el cual lo que importa no son los comienzos ni los finales sino la postulación del entre y el presente de la escritura.

Con espejos reales y ficticios, a tientas, con retazos, leyendo y escribiendo, la cuestión es que $M$ atías realiza una aventura. Los 12 días que transcurren entre su última jornada en Brasil y su vuelta al hogar paterno descritos en $M$ ala onda pueden ordenarse en dos unidades de seis días. Las anotaciones de los 6 primeros días incluyen los sucesos referidos al viaje a Brasil, la vuelta a Chile, a la familia y los amigos. También se incluye aquí la ida a Reñaca y el desencuentro o "traición" y falta del padre. En los otros seis se relata la fuga del hogar, el descenso a otro espacio y el regreso a casa. En la primera unidad se relata un aprendizaje insustancial "lógico, maduré más que la cresta" (p. 27), el que se afirma haber logrado en Río; escenifica las acciones de un andariego, sin destino ni voluntad, aburrido -siempre aburrido-, desvinculado, apestado, desacomodado. Flora M ontenegro diría que "malcriado y autorreferente: una mala copia de Holden Caulfield":

Esta sensación te ha acompañado tantos años como los que tienes, ¿no? Siempre está ahí, nunca desaparece del todo, busca el momento preciso para reaparecer y hacerte recordar que sí, que es verdad, que no eres igual al resto. Eres 
peor (...). Eres peor, pero nadie lo sabe: ése es tu secreto. Es una cuestión de desigualdad, de no saber amoldarse, de ser distinto, nada más. ¿Q uién sabe? Pero da lo mismo, igual duele, igual incomoda, igual te aleja de todos, igual al ejas a todos (p. 129).

El relato del sexto día (8 de septiembre) se inicia con una seriede preguntas sin respuesta, pero queindican una necesidad, una búsqueda, que no encuentra satisfacciones en los personajes que hasta ahora operan como ayudantes en el proceso de formación. El día séptimo, y fundamental en el proceso de individuación, ocurre el descubrimiento de $\mathrm{H}$ olden Caulfield, y contiene la escena que desenca dena la salida del hogar paterno y los posteriores sucesos de la aventura primeray del estado de la cosa pública. La división en unidades de 6 días, la falta del día séptimo de la creación, aquel en que se puede descansar, revelaría la insuficiencia, el carácter incompleto del mundo por la ausencia del padre. N o obstante, la formación del héroe habría ocurrido y éste está en condiciones de avanzar.

En otra ordenación de los capítulos se puede determinar una unidad menor de 5 días (miércoles 3 al domingo 7) y una de siete (lunes 8 a domingo 14). EI día quinto termina con la ausencia del padre, más bien la negativa del padrea ir a buscarlo al terminal de buses al que llega de Reñaca, luego de huir de los amigos, la droga y el alcohol.

El día sexto del relato, el 1'0 de lo que sería una metáfora de los 7 días de la creación del "mundo" de M atías, es el de las preguntas, secuencias que culminarían el domingo 14 de septiembre, día en que el héroe pueda ya reflexionar sobre lo sucedido y tener una proposición sobre su acción:

H ace una semana, justo el domingo pasado, bautizamos al Felipe. También había llovido, también había sol. Los domingos tienen esa particularidad de parecer todos iguales, pero no lo son. $\mathrm{H}$ a transcurrido demasiado tiempo desde el domingo pasado, mucho más que una semana. Es como si todo hubiera ocurrido hace años... (p. 331).

Estos serían los 7 días de la creación de un héroe en una sociedad en la que reina el simulacro, pero falta el mito y/o lo superior. Un héroe burgués para un mundo en el queno hay que ascender, sino en el que se impone sobrevivir y, tal vez, esperar. La renuncia a la aventura, la postergación de la libertad, la vuelta a un orden que no es tal, reconfiguran la noción de aprendizaje en la sociedad dominada por la simbólica del consumo y la ética del no cambio y desterritorializan el lenguaje literario moderno, de narradores "maduros" y lo envían a un espacio lingüístico dominado por los signos y símbolos de la cultura mediática y audiovisual. Aun así o porque debe ser así, M ala onda revela la formación del héroe, que, al igual que los más conspicuos integrantes del paradigma, habla, 
toma decisiones, actúa con mesura, memoria e inteligencia, constituyéndose "no sólo en función del mundo para ordenarlo y hacerlo comprensible sino en referencia y relación con el mundo exterior incrustado en el campo narrativo imaginario" (Jitrik 1975:32). Por ahora, pondrá juntos los restos del padre, que podrían ser también un anticipo de los restos del orden patriarcal de otras nove las, y sobrevivirá, no sucumbirá como Ximena, el personaje sacrificado en la novela por su diferencia. Entonces a $M$ atías le gustaría creer que la cosa se apaciguó, que lo que nos espera es la calma". Sin embargo, el Alejandro Paz de Chile, el que opina que lo peor es acostumbrarse, antes de irse al exilio, le regaló un montón de revistas y "El coyote se comió al Correcaminos" de Josh Remsen y éste - que es como H olden Caulfield si hubiera nacido veinte años despuésha dicho cosas inquietantes:

- $\mathrm{H}$ ablando de fe y confianza, ¿crees, por ejemplo, que el C oyote efectivamente se puede comer al Correcaminos como titulaste tu último álbum?

-Supongo - sería increíble. Eso es lo que espero. Va a correr sangre, claro, pero ya era hora. ¿N o?

M atías se salvó, por ahora; M atías sabe que algo allá afuera, allá abajo, lejos de esas tremendas casas mediterráneas, algo lo espera. Por ahora, aguarda, pedalea y respira. Por ahora, $M$ atías, el autógrafo, escribe. En un sentido éste es el día 7 de la creación, en otro éste es el día 6 de la creación.

\title{
II. LA BIOGRAFIA DE UNO Y LAS HISTORIAS DE LOS OTROS: THE SLEEPER MUST BE AWAKEN
}

\author{
Anoche conocí a H olden Caufield. Fue \\ algo químico, absolutamente arrollador. \\ No podría creerlo. Ya no estaba tan solo. \\ Alberto Fuguet \\ ¿Algunos versos pueden sal var la vida? \\ -M ás que salvarla, redimirla que no \\ es lo mismo \\ - ¿Y los versos de otro, los versos leídos? \\ - Eso, claro que sí, se pueden. \\ Incorporar a tu vida y fijan algo. \\ Tuyo para siempre. En todo caso, \\ Lo que sí consiguen es hacerte la vida \\ Más soportable.
}

JaIME GIL DE BIEDMA

En su libro demayo de 1993, descrito por él como "un ensayo deinterpretación del desarrollo de la novela chilena del siglo XX", José Promis establece las es- 
tructuras generales y más características de la evolución de la novela chilena durante ese siglo. El crítico ordena o "disciplina" la narrativa nacional en categorías o conceptualizaciones como novela dela descristalización, novela del fundamento, novela del acoso, novela del escepticismo, novel a dela desacralización. En este último programa narrativo - el de la desacralización- que alcanza su madurez en los ultimos años del milenio pasado, reconoce cuatro series y varias subseries. Promis escribe que, como su nombre lo indica, en este proyecto se trata de un modo de interpretación literaria que persigue subvertir, cuando no negar radical mente, el sistema de categorías estéticas y los modos y contenidos de representación inaugurados por los programas narrativos anteriores. Esta actitud desacralizadora es, afirma Promis, el resultado de un proceso que comenzó a incubarse con lentitud en las primeras manifestaciones novelescas del período, queseacentuó posteriormente favorecido por el clima de renovación social que viviera el país a partir de 1970 y que, finalmente, adquirió una dimensión de doloroso dramatismo después del gol pe de Estado de 1973 (Promis 1993:197). En las novelas de este período el acto de narrar terminó siendo el resultado de una consciente consecuencia de un concepto del género que hacía suya la definición de la obra literaria como "estructura de lenguaje" y según lo cual el acto de narrar es un proceso de introspección artística antes que una representación de "peripecias" exteriores. Los relatos de este período se caracterizan también por estar "traspasados por la presencia del referentehistórico" y por imponer un "concepto combativo y polémico del discurso que se dirige no sólo a desterrar del espacio de la representación las imágenes agónicas del comportamiento histórico, sino también a remecer la mentalidad y los hábitos del lector tradicional" (Promis 1993: 247 y 248).

En cuanto a los personajes, en la novela de la sacralización abundan aquéllos marcados por una condición de ajenidad y extrañeza y uno de los motivos más representativos del programa es del "extraño entre los hombres".

Fuguet no aparece mencionado en el libro de José Promis; sin embargo, $\mathrm{M}$ ala onda, aparte de pertenecer al período cronológico señalado, presenta varias de las características determinadas por el crítico para la novela chilena de fin de siglo. Posee el carácter interrogativo, la constante referencialidad histórica y espacial ("Io que a uno le tocó"), la subversión de los modelos, la extrañeza del protagonista, el modelo agencial el egido y la estructura y contenidos del relato que se constituye con los retazos y restos de las grandes novelas de aprendizaje, denuncia o compromiso social. Asimismo están las marcas de la novela familiar y la problematización del salón, un espacio privilegiado por la novela anterior ya demonizado por Donoso y "sudaquizado" por Eltit, quienes lo lanzan a los márgenes y la otredad.

En M ala onda se trata de relatar, historizar y reducir un mito de la novela 
chilena al tiempo que se diversifica el modelo del "diario de vida" y la presentación de una biografía y la obtención de la escritura. M atías Vicuña, quien no lucha por la conquista de bienes, de poder 0 de dama, se autorrepresenta escribiendo y seleccionando unos días de su vida que cifran la constitución de una conducta y exponen su encuentro con la escritura. Su propio discurso, emitido en presente, como en presente ocurren los hechos, está precedido por un epígrafe, tomado de una letra musical - de "Faith no M ore" ("N o másfe")-, en el cual se nos revela la condición espiritual, el estado sicológico de quien a continuación toma la palabra, comenzando por ratificar el estado decarencia anticipada en el epígrafe que opera también al revés, como acto de selección de escritura que ratifica un escrito ya concluido. Mala onda se plantea así, de manera heterodoxa, como un tipo de escritura que se desenvuel ve en torno a la imposibilidad de totalizar, más aún en una novela en la que se narran unos cuantos días de la vida de un sujeto cuyos encuentros y acciones son insuficientes en su ejecución activa -en el presente-, aun cuando sean proyectivos en su opción por la vida posible y por ocurrir.

D e esta manera, "si ciertos elementos formales de la autobiografía convencional (¿de la vida?) hacen imposible la inclusión de algunas escenas o circunstancias - la de la muerte del sujeto escritor y su consiguiente mirada total izadora-" (Fernández 1991:125), en la novela de Fuguet, deudora de Papelucho, no encontraremos incluidos sino ciertos acontecimientos que parecen "abrirle los ojos" y la capacidad de pensar sobre una mínima parte de lo que tendremos que llamar realidad y su enraizamiento en ella.

Como en toda autobiografía, hay en M ala onda dos escenas básicas y que tienen gran importancia en el ámbito dela filiación y la afiliación que ocurre en el texto: una es la salida de la casa familiar, y que ya hemos glosado, y otra, el aprendizajey ejercicio dela escritura. La importancia de dichos "autobiografemas" en un libro que hemos descrito como novela de aprendizaje y diario de vida y que hemos anticipado como proceso de individuación del personaje a través de la lectura y la audición de música y sus letras correspondientes, justifica la reproducción literal de los siguientes párrafos de "La novela familiar del autobiógrafo: Juan G oytisolo":

D ado que el autobiógrafo es, por definición, un escritor (grafo), resulta máso menos obligatoria una descripción de la adquisición de la letra escrita. ¿C ómo lleguéa escribir? es una pregunta implícita en cualquier autobiografía, y es una pregunta que funciona a dos niveles distintos. Por una parte, la contestación a esta pregunta consistiría en la narración - muy frecuente en el género, por cierto- de aquellas escenas domésticas o escolares en las que inculca el manejo del alfabeto. A otro nivel, el texto autobiográfico entero se puede considerar una respuesta a esta pregunta; la narración de todas aquellas peripecias de la 
vida que desembocan en el presente del autobiógrafo: un presente, inevitablemente de la escritura.

Ya que el autobiógrafo es un individio (auto) con una vida (bio) narrable, resulta imprescindible una descripción de la adquisición de un nombre propio, de una vida propia. A lo largo de la historia del género, lo narrable tendrá origen en el abandono o la expulsión del hogar doméstico, familiar. El hijo pródigo será el gran modelo autobiográfico: se entiende que su hermano mayor - casero- tiene poco que narrar. Las escenas de ruptura con la familia suelen ocupar un lugar privilegiado en la narración autobiográfica, y la actitud del autobiógrafo hacia esa ruptura puede determinar, en gran parte, el tono del texto entero. ¿Se trata de un error, de una transgresión?Tono nostál gico, elegíaco. ¿0 setratamás bien deunaliberación?Tono optimista del seif-mademan. Un lector conocedor de los 'clásicos' del género podrá evocar con facilidad todo un collage de estas escenas cruciales: despedidas, rechazos o evasiones de la familia. San Agustín se despide de su madre y emprende el camino hacia Roma. Santa Teresa resuel ve su "batalla y contienda" entre "el amor del padre" y "el amor de D ios": entra en el convento. Sarmiento echa abajo la higuera de su madre. Benjamín Franklin huye de su familia y de Boston: en Filadelfia comenzará a participar en la fundación de una nueva sociedad, una nueva 'familia' (Fernández 1991:55-56).

Todo lo anterior, válido para los discursos modernosy/o canónicos del géne ro, ocurre de una manera no canonizada en $M$ ala onda. En ésta, M atías, en un impulso (luego no sabe cómo llegó hasta donde está), abandona su casa, realizando el autobiografema de la salida, hecho que va ocurriendo paralelo al trato con las escrituras de otros que anticipan o anteceden la suya.

En la realización de este autobiografema, el del encuentro o la adquisición de la escritura, resulta de vital relevancia el acto de oír canciones -el sitio de la historia- y leer todo tipo de textos escritos, pues ellos van preparando y desembocan en laformalización del propio alfabeto escritural exhibido en la narración que es $M$ ala onda como diario ejecutado en presente formal o ficticio.

M atías, quien también escribe cartas, tiene dos iniciadores literarios bastante canónicos. Ellos son Flora M ontenegro, la profesora de castellano, y Alejandro Paz. También un amigo y gran lector, $\mathrm{N}$ acho, y muchos rockeros y cantantes pop, cuyas letras lee como literatura, son agentes importantes en el encuentro también facilitado por la familiaridad con revistas, diarios, comics, novelas, cine, series televisivas. La Tercera, Pent-house, Village, Voice, Condorito, Hustier, Interview, Surfer, El M ercurio, H oy, Rolling Stones, National Geographic, La ciudad y los perros, Los jefes, Los cachorros, Lolita, Casa de campo, El Quijote, Las buenas conciencias, Boquitas pintadas, Sobre héroes y tumbas, Coronación, El obsceno pájaro de la noche, Palomita Blanca, D esde el Jalgh Huckieberry Finn, la mención de Philip Roth y, por cierto, TheC atcher in the Rye de Salinger deno- 
tan un espacio altamente letrado y/o de evidentes referencias literarias, en coexistencia con productos audiovisuales propios de una época determinada por la cultura mediática, de la imagen y el sonido. Ello también concuerda con la valoración y mención de series televisivas y filmes -El Chavo del 8, Combate, Gigoló americano, M ad M ax, Xanadú, C astillos dehielo, N ace una estrella, C aradura, Stark y H utch- y con una larga lista de notables temas y cantantes pop que constituyen el paisaje cultural híbrido, posmoderno y nada de pobre con el que $M$ atías intenta comprender y responder a su desasosiego.

Esto muestra, 0 al menos indica, que $\mathrm{M}$ ala onda realiza y cumple con los deberes del relato autobiográfico, liberando de una (im)posible gravedad, uniformidad o grandilocuencia el origen de su escritura y dándole el talante posmoderno que valida la mezcla, la hibridez de la llamada alta cultura, con los productos mass-media y la cultura basura. $\mathrm{H}$ ay en la novela, en la que un personajesellama Papelucho, como el otro escritor dediario de vida, al go así como la búsqueda de un modelo de conducta que sea también un espejo de escritura. Por eso, por ejemplo, se recuerda y explica que a $\mathrm{N}$ acho le gusta $\mathrm{L}$ a ciudad y los perros y Día domingo "porque tenía que ver con el agua y la competencia y la propia vida del amigo en el internado al que su padre lo envió".

El encuentro con el espejo, el cómplice o compañero escritural, ocurre en el día séptimo y resulta, como ya se sabe, ser $\mathrm{H}$ olden Caulfield, el protagonista de Salinger, cuyo libro ha sido insistentemente recomendado por Alejandro Paz y cuestionado por Flora M ontenegro. El encuentro se percibe como un hecho extraordinario, premonitorio e incluso aleccionador. D e Caulfield se destaca una gracia: que sea capaz de hablar, de sacar la voz:

Anoche conocí a $\mathrm{H}$ olden $\mathrm{C}$ aulfield. Fue al go químico, absolutamente arrollador. No podía creerlo. Ya no estaba tan solo, me sentí menos mal. H abía encontrado un amigo. M i mejor amigo. Había encontrado un doble.

Por fin.

Fue casualidad. Como en las películas. Justo cuando uno cree que ya no hay caso, que todo está perdido, que jamás, ni por casualidad, va a salir del hoyo o desprenderse de esa horrorosa sensación de estancamiento que hace que uno sólo se aburra, que todo dé lo mismo, eso de no sentir ninguna satisfacción con nada ni nadie, sucede al go que logra descolocar.

Q ue me descolocó, digamos. Q ue me mató.

Eso fuelo que me pasó con $\mathrm{H}$ olden. $\mathrm{C}$ on $\mathrm{H}$ olden $\mathrm{C}$ aulfield. Es como si lo conociera de toda la vida al $\mathrm{H}$ olden. Eso es lo genial. Siento que conozco su voz, si me llamara, por ejemplo, me bastaría escuchar su timbre para reconocerlo y decirle: "H ola, $\mathrm{H}$ olden, qué onda, por quéno nos juntamos". Lo extraño de todo esto, claro, es que Holden no existe: es sólo un personaje. Lo otro es que habla inglés. Esto es lo raro: lo lé -o más bien mehabló, porque eso es lo que hace, hablar- en inglés pero yo sentí que lo hizo en español. 0 mejor 
dicho: en chileno. Pero quizás ésa sea su gracia: ser capaz de hablar, de sacar la voz. Y es como si no fuera sólo su voz, es como si fuera la voz de todos. 0 , al menos, como si fuera la mía.

Esto me asusta porqueH olden es un gran tipo, lo quiero a cagar, me parece admirable y total, pero su final no fue precisamente el mejor: Terminó mal, muy mal. Encerrado en una clínica, como la Ximena Santander: D espués no se sabe. Es un final abierto, como diría la Flora. Aunque tal vez no, porque a mí me queda más que claro lo que opina Salinger, que es el tipo que lo escribió, y cuáles son las opciones de H olden. Este mundo, está claro, no está hecho para gente como Caulfield. Pero eso él lo sabía. Lo que no sabía era el costo que había que pagar por ser distinto. Eso me mató (pp. 233-234).

A partir de ese momento, y hasta el encuentro con Josh Remsen, y a excepción de la música que escucha el padre en el auto, prácticamente desaparece la mención detemas musicales del relato poseído ahora por el espíritu deC Culfield. La novela de Salinger aparece como el espejo de una conducta y de una escritura designada desde su epígrafe por la relación intertextual múltiple que proyecta un estar "entre" y la necesidad de un encuentro que salve del vacío y la caída: "Jore see, I'm somewhere in between. M i life is falling to pieces / somebody put me together". Somebody put me together. "Q uiero contarle a Alejandro Paz sobre $\mathrm{H}$ olden y agradecerle que me haya prestado el libro. Es raro: hoy, a esta hora de la mañana me siento mucho más cerca del Paz que antes. Y llamó de nuevo. El Paz no está. Pero así es el mundo: inversamente proporcional a las necesidades y deseos de uno" (p. 234). Somebody put me together. El discurso de $M$ ala onda deviene encuentro y mimesis de $M$ atías con un personaje culto que está lejos de la heroicidad moderna. Vicuña, como Caulfied, marcan sus orígenes, escriben sus experiencias, expresan el malestar personal y con su cultu$\mathrm{ra}$, emprenden un viaje arbitrario hacia ninguna parte, gastan dinero, van a un hotel, y vuelven o son devueltos a casa. Sin embargo, aparte de pequeñas dife rencias señaladas por V icuña: por ejemplo, a C aulfield no le gusta $G$ atsby y a él lo mató pues "D aysi era como Antonia y me encantó eso de que las mansiones se enfrentaran a uno y otro lado de la pequeña bahía" y cita de memoria el comienzo de la novela: "M i padre una vez me dijo cuando sientas la necesidad decriticar a alguien recuerda que no todas las personas en el mundo han tenido las mismas ventajas que tú" (p. 246). A parte, también, digo de que M atías descubra que es medio judío y $\mathrm{H}$ olden no, 0 de que éste adore a Phoebe y admire a su hermano mayor y que $M$ atías deteste a sus hermanas, no tenga hermano mayor y escriba un diario, hay una gran diferencia entre estos dos relatos significados por personajes juveniles que expresan hacia el final del relato un mismo sentimiento: echar de menos a aquéllos de los que se ha escrito y con los que se ha escrito. 
La gran diferencia está marcada por el desenlace de la fuga y por la contextualización histórica y afectiva del retorno al domicilio familiar. H olden esconducido de regreso, sin una exposición de los hechos y en su carácter de enfermo, debe recibir tratamiento siquiátrico, sin cuidado por no poseer dominio sobresí mismo ni del mundo en que actúa. Por el contrario, M atías es quien, reconociéndose, toma la decisión de regresar, acepta la retracción que en tales circunstancias es saber asumir su ser físico, la mirada y razón de los otros y, sobre todo, identificar un valor 0 deber prioritario y una debilidad contingente 0 eventual.

La actitud generosa y filial, el ejercicio de memoria y voluntad, este salvarse justito, que hacen de V icuña un personaje muy chileno y familiar, y que coexisten con la asunción del lado "oscuro" de su identidad racial, su miedo y la postergación de su aventura de libertad, derivan en gran medida de un nuevo encuentro, otro encuentro. O bviamente, lo dije, hay un reconocimiento y un encuentro físico con el padre y una gran simpatía por H olden, pero es el contacto con otro héroeficticio el que indica un camino y permite el tránsito hacia un saber maduro y propositivo quejustifica el actuar del presente sin negar el deseo y el "peligro" o posibilidad del futuro. El encuentro es nuevamente permitido por la letra impresa, pero en este caso cifrando los dos saberes que han determinado el aprendizaje del adolescente y la comprensión de lo que el mundo podía reportarle si imitaba totalmente a $\mathrm{H}$ olden.

La escritura y la música. Setrata del encuentro con el VillageVoice y la entrevista a Josh Remsen,

el primer rockero post-punk, antidisco, criado en el exclusivo U pper East Side de M anhattan, hoy un héroe del East Village, lugar donde, después de años de vagabundeo compulsivo que lo llevaron desde las plantaciones de marihuana de Jamaica a los bares más duros de D ublín, este chico frágil pero tenso, de veintidós años, que nunca terminó la secundaria pero mete a Joyce sin temor en sus erráticas y embriagadoras letras, ha encontrado algo que, por ahora al menos, se atreve a llamar hogar. Por fin (p. 303).

Por fin M atías sabe algunas otras cosas. A través de las respuestas de este rockero judío, criado en barrio exclusivo, vagabundo, marihuanero y al cohólico como él, descubre el concepto hogar, al menos percibe la idea de que tal cosa es lo que busca. El rockero, también fervientemente recomendado por Alejandro Paz, el ambiguo maestro de $M$ ala onda, lehabla dela inocencia, de la pérdida de ésta, del hecho de tomar decisiones, del amor y la salvación. Con él descubre o al menos intuye que

Sí... yo creo que uno a la larga se puede salvar. Es a lo que debemos aspirar. Yo no ando buscando ni la felicidad ni el amor ni la fama. Ando buscando la 
salvación. Confío en poder lograrla. C laro que para ser creyente hay que estar dispuesto a sacrificarse. Si me salvo, todo vendrá después por añadidura. O jalá. - ¿Salvarte de qué?

- Eso es problema mío, pero cada uno sabe de qué se va a salvar. No todos quieren hacerlo, claro... (p. 307).

D espués de este encuentro todo se precipita. A parece el abuelo, se producen incidentes en la Alameda, van al Club de la Unión, se corta el pelo y llega el padrey ocurre lo quetiene que ocurrir. M atías vuelvea casa en una decisión que está entre el miedo y la libertad; entre la generosidad y la incapacidad, entre la cobardía y la inteligencia; pero que es, sobre todo, una respuesta filial y un reconocimiento pertinente de lo real tras una adecuada interpretación de las pruebas. M atías ha decidido salvarse del destino de Caulfied y del de Ximena Santander y está dispuesto a sacrificarse, pues si se salva todo vendrá después. Además cada uno sabe o debiera saber de qué se va a salvar. Este acontecimiento, paralelo a la escritura, constituye un fin en sí mismo y concentra en gran medida el interés narrativo de una novela que da pruebas de la imposibilidad de la aventura de la libertad en un mundo sin Dios, autoridad o ley que permita el fluir, con padres despojados de toda ética y vigor y cuyo gran estímulo es preservar los usos y abusos existentes. M atías intuye levemente todo esto, pero sus mediadores literarios y biográficos le permiten descubrir lo que casualmente anda buscando.

Así, aunque de una forma diferente, el héroe es una construcción dinámica y situada. M atías V icuña como Aniceto $\mathrm{H}$ evia, auxiliados por otros relatos, terminan comprendiendo lo que ocurre a su al rededor, a su lado: "Y unos pasos más allá y quizás más lejos - todo lo vería y lo sentía, los colores, los sonidos, el olor del viento y de las personas, los rasgos de los seres y de las cosas y todo ello se unía en mí, crecía y me hacía crecer, ¿para qué?, no lo sabía", afirma el héroe de $M$ anuel Rojas al final de su aventura de H ijo de ladrón (1969: 556). Como un eco, M atías también encuentra la hora de partir. "Empiezo a descender. La pendiente está brava y con cada pedaleo más velocidad agarro. EI viento es puro, tan helado que corta. Pero sigo, me gusta..." (p. 335).

A hora bien, si, según Jost, la noción de elección es fundamental en las novelas de aprendizaje, he aquí una novela, $\mathrm{M}$ ala onda, en la cual, junto a la comprensión del mundo que se habita y el autoconocimiento adquirido, se expone una elección instaurando un sistema ideológico mostrado a través de las marcas del narrador responsable del diario referido en tiempo presente en una coincidencia retórica entre el presente del discurso y de la historia.

Todo esto es válido, en la medida en que pensemos y postulemos que la novela de Fuguet es algo más que un relato sobrevalorado donde "todo es tan 
obvio y sin sentido" o donde se pretende universalizar la problemática de un personaje que, seamos sinceros, no le interesa a nadie... (p. 252) o una versión de Papelucho crecido y sin gracia.

\section{PADRE MIO, ¿POR QUE TE HAN ABAN DONAD O? $O$ EL ORDEN DE LAS FAMILIAS}

$H$ an de distinguirse dos grados de iniciación en la mansión del padre. D el primero, e hijo vuelve como emisario, del segundo, con el conocimiento de que yo y mi padre somos uno...

$$
\text { Joseph CAm Pbell }
$$

Se podría decir queM atías Vicuña, como un remedo deH amlet, termina amando y honrando a su padre y albergando completas reservas en relación a la madre, quien es el sujeto de la traición en el texto. También se podría afirmar con Levinas (1993) que en M ala onda es el hijo quien debe recuperar la unidad del padre, permaneciendo exterior a él, pues en el texto se recrea un encuentro y una relación con el otro en la que éste es siempre radicalmente otro y, no obstante, ese otro quees el padrees yo, pues el yo del padre tienequever con una alteridad que es suya, sin ser su posesión ni propiedad. Concluir, tal vez, que sustituir, es decir, estar o proponerse en lugar de otro, alcanza en la novela de Fuguet una figuración diferente, desublimada e incluso carnavalizada y simbolizada en el signo trivial de un perfume, pero igualmente trascendente en cuanto - ¡Esto es lo que hay!- a la asunción y aceptación de una filiación que ocurre paralela a la aplicación con otros héroes y otra ética.

$\mathrm{Si}$ aceptamos la descripción de $\mathrm{M}$ ala onda presentada antes, podemos afirmar la presencia, fundamental en estetipo de textos, de un personaje privilegiado, el padre, y de un espacio, con cronotopo - diría M ario Rodríguez siguiendo a $D$ eleuze- donde ocurren los intercambios esenciales en la novela burguesa. Todo lo anterior, inscrito en nuestro análisis de $M$ ala onda, en la tradición de la continuidad y la ruptura que Edward Said ha descrito como aquella que lleva al escritor a reemplazar los lazos de filiación (vínculos biológicos, hereditarios, familiares) por otros lazos de afiliación (vínculos intelectuales, morales o espirituales). Esto que, como ya hemos anotado, implica la ruptura con la familia, el hogar, la clase social, la nación, las creencias tradicionales - los grandes relatoscomo etapa necesaria para lograr la libertad espiritual e intelectual (Said en Fernández 1991:51), aparece desvanecido en la novela de Fuguet como desvanecida está la figura del padre. También se sabe que el género autobiográfico es el más adecuado para describir esta ruptura y sustitución. Fuguet, que opera 
desde la tradición y la fuga, recorta 0 articula los saldos de esta búsqueda impre sa en los relatos que proclaman la ideología guerrera del héroe que ha encontrado su lugar, su frente de lucha en el mundo. Así en la adecuación - no negación del modelo- a un estado de la cuestión de los padres, los valores, e incluso los burdeles, $\mathrm{M}$ ala onda proclama su "calumnia" de relato menor, confirmando que no es la hora del heroísmo inmolador, sin destino. El gran héroe de $M$ artín Rivas - en el hoy de la historia, un confundido adolescente- abandona el salón para cruzar las zonas de peligro de su aventura y regresar a él para cumplir la parodia de sustituir al padre abandonado por la madre. Resistir 0 alzarse en armas. No hay aquí venganza ni reemplazo en la gestión del poder sino mera resistencia en los espacios donde el poder opera desde un lugar exterior y contundente. Cartografía, entonces, de los espacios y movimientos de un grupo social, los once días de la vida de Vicuña dan cuenta del estado ni trágico ni cómico del esquema familiar chileno, al menos de una clase que vive una comedia de enredos y amoríos en el seno de una familia de la alta burguesía. En el seno de aquel grupo que puede volver a dormir tranquilo, adormecido por el bienestar y otros productos, el 14 de septiembre de 1980.

"M e sente y miré hacia fuera, tratando de no pensar en nada, pero me pre guntaba de dónde sacaba mi padre ese tipo de coca y por qué el tío Sandro le tomaba la mano a mi madre". Estas son las preguntas que $M$ atías se hace justo antes de abandonar el gran salón familiar, "que brilla dorado bajo las luces y los candelabros" (p. 271), y en el cual secumple el ritual, el simulacro de la sociabilidad mundana que gusta de exhibir el éxito e idolatra el hedonismo.

Ando de chaqueta, una chaqueta de tweed gris. Idea de mi madre. Ella me la compró y ella me obligó a ponérmela. Frente a mí, al otro lado del living, está mi padre. Recuperado, por cierto. Aún tiene el pelo húmedo. También anda con una chaqueta de tweed, pero la suya es café. Está ju gando al barman, rodeado de los tragos que compramos en esa botillería de EI Bosque con Apoquindo. D ejamos el Jumbo en cosa de segundos y ninguno de los dos se atrevió a comentar el espectáculo. Ahora es como si nada hubiera pasado y él, después de la ducha, su afeitado, su Azzaro, está perfecto, coqueteando con la tía M aría Teresa Ezquerra, a quien le sirve un Tanqueray con G inger-Ale, más una rodaja casi transparente de limón. No tengo muy claro quéestoy haciendo aquí, pero mi madre entró a mi pieza y me preguntó si iba a salir. Lo pensé un instante y, la verdad, no se me ocurrió dónde podría ir. Le respondí que no, que me iba a quedar en casa (...).

Rodajas de limón, de lima y de naranja. Azúcar flor, marrasquinos rojos y verdes. Trozos de piña. Aceitunas para el martini seco. Agua mineral, con y sin gas, jugo de tomates. Sal sa tabasco. Bitter. Crema de coco. Agua tónica. Todo. D ecido prepararme un Bloody M ary a la M ejicana, sin aí. N o hay demasiada gente pero la selección fue rigurosa, me percato. Está el tío Sandro Giulianni, 
que llegó solo, y mi tío Enrique $M$ atte, impecable como siempre. $H$ ay varias parejas que no conozco pero se nota que es gente relacionada con el dinero, y el N egro Ezquerra habla con uno que, por su corte de pelo, tiene que ser militar. También estámi tío Sergio V icuña, el embajador deC hileen Indonesia, que es el que está de santo; y la tal Stella D e C astro, su nueva esposa, mucho menor que él debido a la cirugía plástica que se hizo. En este momento le cuenta a un viejo que se parece a Robert M itchum, pero se llama Armando O rtúzar, lo maravillosas que son las playas de Bali. M i madre, por su lado, está en el sillón principal y conversa con mi tía Lorena, la M aría Teresa Ezquerra, que ya está terminando su gin, y con la mismísima M eche Ellis de O rtúzar, quizás la mujer más millonaria que ha pisado este departamento. La M eche es esposa del Robert $M$ itchum, pero todo el mundo sabe que es ella la que tiene el poder y quien logró que él fuera elegido senador en épocas pasadas. También es presidenta de no sé qué comité de beneficencia, campeona de equitación y madre de dos de las minas más locas y reventadas de C hile (pp. 269-272).

En esta corte de las vanidades, en este salón de las apariencias, al que asisten diplomáticos, empresarios, militares, bellas mujeres, amigos y familiares, el otro mundo aparece representado tan sólo como en una suerte de murmullo o eco traído por la presencia, las afirmaciones y al egatos aislados de al gunos personajes como C armen, la empleada de la casa, quien sabe muy bien que su voz no se oye, pero igual "hay que revolverla". Una mesa Ilena de comida, flores, luces y belleza desencadena el roce de ambas percepciones y deja oír la voz de M atías, quien, obviamente, habla por boca de ganso.

Con la cabeza gacha. El tío Sergio se acerca y mira con atención las carnes y jamones y ensaladas y langostas y frutas y al cachofas rellenas.

- Y después dicen que en $C$ hile no hay qué comer - comenta.

En resto de los concurrentes ríe de buena gana ante el humor y la rapidez del embajador. Yo lo pienso un segundo. Pero no hay nada que pensar, siento. Es lo que debo decir. Y lo digo:

- Por quéno se da una vuelta por las poblaciones y deja de hablar huevadas. M i tío queda lívido. Nadie dice nada. Yo siquiera trato de respirar. Pero no pestañeo.

-Sergio, perdona - interviene mi madre, pero este niño está borracho y no tiene ningún derecho...

- ¿Q uién está borracho, madre?

- Córtala, M atías, que te voy a cachetear aquí mismo.

M iro a mi padre pero él no dice nada. El tío Sandro tampoco.

- Andate a tu pieza. No te quiero ni ver - me grita mi madre. (pp. 278-279).

El desacomodo, el malestar sin clara conciencia (de dónde sacaba mi padre... por qué el tío Sandro le tomaba la mano...) de M atías que se hace voz, y se 
verbaliza frente a las afirmaciones del tío Sergio, es consecuencia del deterioro del padrey la traición de la madre observados por el joven recién un momento antes

en otro rincón, la Stella habla con varias mujeres sobre sus hijos, que están repartidos por todo el mundo. Mi madre, en tanto, le habla al oído al tío Sandro, que suda y se pone rojo. El tío se percata de que lo estoy mirando y le suelta la mano.

M i padre, por su parte, regresa al living, conversa un poco con el tío Enrique y el Robert M itchum y mira, a cada rato, hacia dondeestán mi madre y el tío Sandro que siguen conversando, algo borrachos los dos.

- ¿Cómo está todo? -me pregunta mi padre que, se nota, se acercó porque desde aquí hay mejor vista hacia el rincón donde está mi madre.

- Los pacos están apaleando a los del $\mathrm{N} 0$.

- Te pregunto por aquí, ¿cómo está todo aquí?

- Como lo ves. ¿Te sirvo otro?

-Bueno.

Agarro el vaso, le echo hielo y un buen poco de Etiqueta N egra. D espués lo miro pero él no se da cuenta. Tiene una huella de polvo blanco bajo la nariz. M e acerco otro poco, estiro el dedo y trato de limpiárselo. El salta, se retira y me mira con unos ojos de perro perdido que me atraviesan. Pero la guardia baja le dura sólo una fracción de segundo:

- Q ué te pasa, huevón - me dice con furia y me empuja.

Es el gol pe que estaba esperando, siento, mi madre se ha dado cuenta pero, en vez de acercarse, aplaude y dice:

- Bueno, por qué no comemos. Es buffet. A la americana. Self service. Cada uno saque lo que quiera (pp. 277-278).

Sexo y comida, bebida y sustancias, corren parejos en esta desencantada e insoportable visión de la escena del salón familiar. Borracho y drogado, M atías toma su "T he catcher in the Ryey el frasco de valium". Sin saber cómo, traspasa la frontera de su mundo, representado como en una escena en el salón, y sin internarse nunca por las calles del otro mundo recala en el $\mathrm{H}$ otel $\mathrm{City}$, casi un ícono dela decadencia deun espacio. Esto es un gran salón del centro deSantiago, que como el Club de la Unión, parecen residuos de una elegancia destartalada o envejecida, pero aún protectora y civilizada. Allí conoce aJesh Remsen y busca el álbum "El Coyote se comió al Correcaminos" y "T he sleeper must be awaken" que abrirá sus ojos y su mente hacia zonas de conocimiento posibles para él.

Al rescatellegan, por separado, abuelo materno y padre comprensivo y cómplice. Tras el fracaso fácil, de un personaje tan "fácil" como el abuelo, el rey de las apariencias austro-húngaro-judío: el padre. Intenta convencerlo, incluso con argumentos, con palabras, de volver. El progenitor, que siempre deseó tener un hijo hombre, "incluso antes de conocer a tu mamá, siempre quise tener un hijo 
hombre, un huevón que fuera como yo" (p. 57), quiere llevárselo a casa, pero después de iniciarlo o compartir con él otro u otros delas grandes obsesiones del relato y del mundo descrito: el sexo. Sexo y droga como mediadores en la recomposición de una difícil estructuración de los vínculos padrehijo. Para ello $M$ atías es conducido al nuevo y exclusivo tipo de burdel (salón de intercambio carnal) al uso. The sleeper must be awaken. Allí se produce otra escena fundamental: la descristalización de M atías y la verbalización de su voluntad y expresión de su propia decisión. ¿Volver o virarse?:

Son las cinco y tanto de la mañana, me fijo. M e parece imposible todo lo ocurrido. Incluso eso de haber cambiado de mina o de haber tirado los dos con Solange, mientras la Rebeca picaba más jale y la miraba ansiosa.

- M ira M atías: ni siquiera voy a intentar defenderme, huevón, pero si he sido como soy fue porque...

- Porque mi madre no te pesca...

- Pero yo sí, huevón... No puedo evitarlo ... Parece hipócrita de mi parte, especialmente estando aquí, pero de que la amo, huevón, la amo.

- Díselo a ella.

- Se lo dije ayer. Y hoy.

- ¿Y?

- Está enamorada de Sandro. H ace rato. Por eso dejó él a la Loreto.

Yo no me di cuenta hasta anoche. Nuestra relación anda pésimo desde hace un tiempo. Algo raro había notado, hasta sospechado, pero nunca tanto. $Y$ menos con Sandro que era mi amigo. Q ue es mi socio.

- Estás cagado, papá - le digo, negán dome a creer tanta mierda.

-Si sé, huevón. Si sé. D uele más que la cresta.

D espués seponeallorar tímidamente y seacurruca como un niño a mi lado. Yo le tomo la mano y con la otra le acaricio el pelo. Por la ventana, la oscuridad va cambiando de color. El único ruido que oigo son los sollozos demi padre.

- Vámonos a la casa - le digo-. Q uiero volver (pp. 329-330).

Put me together. La duda era virarse o volver, ya no hay tal. Con su recién iniciada madurez el hijo debe conducir al padre al domicilio familiar. Un hijo que no es un hombre, que empieza un proceso, debe ocupar el centro abandonado por todos. Espacio sin dioses, sin filiaciones paternas continuas (el abuelo es el padre de la madre), el mundo deM ala onda es precario e incompleto y hace espejear irónicamente escenas entre padre e hijo (al abandono del padre en el domingo de la vuelta de Reñaca) y se enfrenta la escena de M atías "recogiendo" a su padre en el burdel.

D e la expresión "Padre mío, ¿por qué me has abandonado?", pasando por "Padre mío, ¿por quéte han abandonado?" a "Padre mío, yo no te abandonaré", transcurre esta novela ambival ente y valiosa en la que no hay investidura, tránsito natural del hijo al lugar del otro, ni canonización o repudio del padre. 
En testimonios de la relación tradición y cambio no hay nada más diferente que el diálogo póstumo entre M artín Rivas y su padre y la escena citada en la que el padre de $M$ atías le habla a su hijo.

D e esta forma $M$ ala onda se incorpora a la ruta de la novela chilena del salón, para mostrar un intercambio escandaloso, el del hijo -apenas un héroe constituido con modelos mediáticos y con apenas voz- protegiendo al padre y actuando como el padre de su padre. U sando una palabra que como un tartamudeo se pronuncia para decidir y continuarse en escritura. Para instalarse en el "salón vacío en el cual se gestó y predijo la traición". "Salvarse o al go así. Uno siempre se salva justito".

D ejemos aparte, por un momento, toda nuestra poética del fracaso y la melancólica glorificación de la derrota como dignidad ante lo ineluctablemente adverso y nuestro desprecio por las pequeñas historias y pensemos que $M$ atías no cagó y que aún tiene toda la vida por delante. Aunque tal vez a M ala onda le sobre al guna página y sus últimos fragmentos expongan demasiado la máquina del deseo de su autor. 0 , tal vez, al contrario: A M ala onda lefalten páginas para (de)mostrar las razones por las cuales M atías logra cambiar su desarrollo en el mundo, me parece que la novela de Fuguet se incorpora al discurso narrativo chileno de una forma fluida, evidente y valiosa.

\section{BIBLIOGRAFIA}

Blest G ana, Alberto. 1981. M artín Rivas. M adrid: Cátedra. Reedición y notas de G uillermo Araya.

Campbell, Joseph. 1984. El héroe delasmil caras. Psicoanálisis del mito. M éxico: Fondo de Cultura Económica.

Cirlot, Juan Eduardo. 1991. D iccionario de símbolos. Barcelona: Edit. Labor.

Eyzaguirre, Jaime. 1973. El héroe en la novela hispana del siglo XX. Santiago: Ed. Universitaria.

Goic, C edomil. 1976. La novela chilena. Santiago: Edit. Universitaria. 4a ed.

Fernández, James. 1991. "La novela familiar del autobiógrafo: Juan Goytisolo", en Anthropos $N$ 125, octubre.

Fuguet, Alberto. 1998. M ala onda. Santiago: Alfaguara, pp. 59-60.

Jitrik, N oé. 1975. El no existente caballero. Buenos Aires: M egápolis.

Jost, François. 1969. "LaTradition du Bildungsroman”. Comparative Literature XXI. 97-115. Larraín, Jorge. 2001. Identidad chilena. Santiago: Lom.

López, Berta. 1987. H ijo de ladrón, novela de aprendizaje. Santiago: Editorial La N oria.

Lukacs, G eorge. 1966. Teoría de la novela. Buenos Aires: Edit. Siglo XX.

0 elker, Dieter. 1986. "El aprendizaje de Jaime Cevallos" en Acta Literaria 10-11, Concepción, Universidad de Concepción.

Promis, José. 1993. La novela chilena de último siglo. Santiago: Edit. La N oria. 
Rodríguez, M ario. 1999. Antología del cuento hispanoamericano. Santiago: Edit. Universitaria.

Rojas, M anuel. 1957. Hijo de ladrón. Santiago: Zig-Zag.

Salinger. J.D . 1997. El guardían entre el centeno. Barcelona: Alianza Editorial.

Soto, Román. 1992. Continuidad y cambio: Ensayossobreel héroeen la novela chilena (18611951). Santiago: M onografías del M aitén.

Skármeta, Antonio. 1999. "El ciclista del San Cristóbal", en M ario Rodríguez, Antología del cuento hispanoamericano. Santiago: Edit. Universitaria.

Suleiman, Susan. 1977. "L'structura d'aprendissaje” en Poetique N ㅇ 32, pp. 468-489.

---------. 1997. "Le Rècit Exemplaire”, en Poetique $N$ 0 37, pp. $24-42$. 